\title{
TRAUMATOLOGIA FORENSE - REVISÃO DE LITERATURA
}

SABES, Amanda Festa ${ }^{1}$

GIRADI, Annita Morais ${ }^{1}$

VASCONCELOS, Rosemeri de Oliveira ${ }^{2}$

\begin{abstract}
RESUMO: A Traumatologia Forense é um dos ramos da Medicina Veterinária Legal e é conhecida por estudar os aspectos médico-jurídicos das lesões causadas por diversos agentes lesivos. A traumatologia é dividida em diversas energias entre elas as de ordem mecânica, física, química, físico-química e biodinâmica. O conceito de trauma pode ser definido como o resultado de uma ação vulnerante que possui energia capaz de produzir a lesão observada. $\mathrm{O}$ estudo da medicina veterinária legal no Brasil engloba as questões judiciais em que os animais estão envolvidos. A traumatologia forense vem ganhando destaque no país graças ao aumento dos casos de crimes envolvendo desde animais domésticos até os selvagens.
\end{abstract}

Palavras chave: Trauma. Lesões. Energias.,

\section{FORENSIC TRAUMATOLOGY - A REVIEW}

SUMMARY: The Forensic Traumatology is a branch of the Legal Veterinary Medicine and is known for studying the medical-legal aspects of injuries caused by various harmful agents. The trauma is divided into different energies including the mechanical order, physics, chemistry, physical chemistry and biodynamic. The concept of trauma can and be defined as the result of a vulnerante action that the energy is capable of producing the lesion. The study of veterinary forensics in Brazil includes the cases in which animals are involved. Forensic traumatology has been gaining importance in the country thanks to the increase cases of crimes involving wild and domestic animals.

Keywords: Trauma. Injury. Energy.

\section{INTRODUÇÃO}

A Medicina Veterinária Legal possui diversas definições entre elas "É a aplicação dos conhecimentos de Medicina Veterinária para atender adequadamente as demandas legais da sociedade, sejam profissionais, oficiais e judiciais" (BANDARRA, 1999). A utilização dos conhecimentos médico veterinários em questões judiciais não é recente. No Brasil, ela está prevista na legislação desde 1933, quando o exercício da profissão Médico Veterinária foi regulamentado pelo Decreto $n^{\circ} 23.133$, de 09 de Setembro de 1933. Nessa ocasião, tal decreto estabeleceu como função privativa do Médico Veterinário a realização de perícias em questões judiciais em que animais estejam envolvidos, posteriormente essa matéria foi ampliada e publicada em forma de Lei ( $n^{\circ} 5517$, de 23 de Outubro de 1968). Desde então, o uso dos

\footnotetext{
${ }^{1}$ Graduada em Medicina Veterinária pela FCAV/ UNESP Jaboticabal. Mestre em Medicina Veterinária na área de Clínica Médica Veterinária e atualmente Doutoranda pelo Programa de Medicina Veterinária da mesma Instituição. ${ }^{2}$ Professora Assistente Doutora do Departamento de Patologia Veterinária da FCAV/Unesp Jaboticabal.
} 
conhecimentos médico veterinários pela Justiça aumentou paulatinamente, passando a ser aplicado em questões relacionadas à saúde publica, defesa do consumidor, defesa da fauna, entre outras (MARLET; MAIORKA, 2010). Dentre as diversas especialidades presentes na Medicina Veterinária Legal, a Traumatologia Forense vem ganhando destaque devido à demanda da sociedade na coibição dos crimes contra a fauna (MARLET; MAIORKA, 2010).

\section{REVISÃO DE LITERATURA}

A Traumatologia Forense pode apresentar diversas definições entre elas: "é o capítulo da Medicina Legal no qual se estudam as lesões corporais resultantes de traumatismos de ordem material ou moral, danosos ao corpo, a saúde física ou mental” (CROCE; CROCE JUNIOR, 1998). A traumatologia é dividida em energias de ordem mecânica, física, química, físicoquímica e biodinâmica. (DEL CAMPO, 2009).

\section{ENERGIAS DE ORDEM MECÂNICA}

São aquelas que incidindo sobre um corpo modificam seu estado de repouso ou movimento. Podem atuar de várias maneiras conforme a natureza dos agentes que as veiculam. Levando-se em consideração a relação entre o corpo e o instrumento causador de uma lesão, verifica-se que as lesões podem ser produzidas pela ação do instrumento sobre o corpo (tornandose um meio ativo), pela ação do corpo sobre o instrumento (meio passivo) ou de maneira mista, quando um atua sobre o outro (DEL CAMPO, 2009).

A gravidade da lesão é dependente da intensidade com que a energia mecânica atinge o corpo, da sede e natureza da lesão e da maior ou menor resistência tecidual (DI MAIO; DI MAIO, 2001). Conforme a superfície de contato, o modo de ação e as características das lesões, os instrumentos classificam-se em: de ação simples (perfurantes ou punctórios, cortantes e contundentes) e de ação composta (perfurocortantes, perfurocontundentes e cortocontundentes) (DEL CAMPO, 2009). É importante resaltar a necessidade de examinar corretamente o animal, para estabelecer se a lesão advém de um trauma agudo ou uma lesão com caráter crônico. Em muitos casos, o animal não apresenta um sinal externo de trauma, sendo o mesmo somente diagnosticado em exames internos (MERCK, 2007). 


\section{Instrumentos perfurantes ou punctórios}

Esses instrumentos agem por meio de pressão exercida sobre um determinado ponto (FRANÇA, 2008). São finos, alongados e pontiagudos causando lesões de pouca repercussão na superfície corpórea, mas de profundidade apreciável. Na maioria das lesões, as fibras de tecido são separadas, porém não seccionadas. Estiletes, pregos, agulhas, dentes (mordedura) são exemplos de instrumentos perfurantes ou punctórios (DEL CAMPO, 2009).

O orifício de entrada da lesão geralmente é regular, de bordos lineares, possuindo abertura estreita. A lesão produzida é uma solução de continuidade apresentando trajeto linear, pouco sangramento e geralmente o orifício de saída apresenta diâmetro menor em comparação ao de entrada, devido à elasticidade da pele (FRANÇA, 2008).

\section{Instrumentos cortantes}

Os instrumentos cortantes agem por meio de pressão e deslizamento sobre a pele ou tecidos dos órgãos. Os mais utilizados são facas, lâminas, navalhas e bisturis (DEL CAMPO, 2009). As lesões provocadas apresentam o nome de incisas e possuem como características: profundidade maior no ponto de origem, margens lisas e regulares, ausência de região de contusão, região média mais larga e profunda, existência frequente de cauda de escoriação ou de saída e a hemorragia geralmente é abundante (DEL CAMPO, 2009).

\section{Instrumentos contundentes}

São aqueles que agem pela ação de uma superfície. Podem ser sólidos, líquidos ou gasosos desde que atuem sobre pressão, explosão, torção, distensão, descompressão, arrastamento ou por outro meio como mãos, automóvel, jato de ar, entre outros. A lesão possui superfície plana, podendo ser lisa, áspera ou irregular (DEL CAMPO, 2009). Como os animais apresentam suprimento sanguíneo reduzido na pele, quando comparado com os humanos, contusões externas não são comumente vistas na superfície da pele (MERCK, 2007). Quando vistas nos animais, é usualmente causada por força severa que geralmente não ocasiona sangramento na pele, mas também nos tecidos adjacentes. Um animal vivo pode ter sofrido diversas lesões, porém não apresenta sinais externos das mesmas, além de vermelhidão nas áreas, o que dificulta sua identificação. Em casos como esse, e em todos os outros em que se suspeita de trauma, exames de imagem como radiografias e exames laboratoriais, podem revelar a verdadeira evidência de uma lesão aguda ou crônica (MERCK, 2007).

As lesões contusas segundo Croce e Croce Junior (1998) englobam: 
- escoriações: também são denominadas de erosão, escara ou abrasão. São superficiais e geralmente produzidas por deslizamento, em que apenas a derme é atingida, fluindo serosidade e sangue, sendo resultado da ação tangencial dos meios contundentes.

- equimose: ocorre devido ao rompimento de vasos sanguíneos superficiais ou profundos. A intensidade da equimose depende do instrumento e de seu grau de violência. As equimoses superficiais apresentam sucessão de cores, decorrentes das alterações cromáticas por que passa a hemoglobina em sua metabolização e absorção pelo organismo.

- hematomas: são coleções sanguíneas formadas pelo extravasamento de sangue oriundo de vasos de maior calibre. Normalmente se apresentam em relevo na pele, e sua resolução é mais lenta em comparação com a equimose.

- concução cerebral: é o mais leve dos acometimentos cerebrais. Normalmente é traduzido por uma descarga no sistema nervoso central sem lesão, que se manifesta por perda temporária dos reflexos, do controle dos esfíncteres e da consciência (no caso de humanos).

- contusão cerebral: decorre de lesões microscópicas e macroscópicas do encéfalo que pode ou não estar localizada próximo a área traumatizada. Aos sintomas de contusão cerebral podemse acrescentar as convulsões e espasmos.

- contusões ósseas: são microfraturas e pequenas hemorragias decorrentes da ação de instrumentos sobre os ossos, sem que ocorra ruptura de tecido ósseo.

- fraturas: são soluções de continuidade, parciais ou totais, do tecido ósseo em consequência de mecanismos de compressão, flexão e torção.

- luxação: é o deslocamento de dois ou mais ossos cujas superfícies articulares deixam de manter suas relações de contato que lhes são comuns.

- entorse: é a lesão dos ligamentos pela realização de um movimento que vai além dos limites fisiológicos da articulação.

Os ferimentos contusos assumem com frequência a conformação do instrumento que os produziu. Outras vezes produzem ferimentos de natureza variada, de grandes proporções, sendo difícil distinguir o agente lesivo. Geralmente as lesões apresentam bordos irregulares, pouco sangramento, integridade dos vasos, nervos e tendões no fundo da lesão além dos ângulos tendendo a obtusidade (DEL CAMPO, 2009).

\section{Instrumentos perfurocortantes}

São geralmente dotados de ao menos uma ponta e pelo menos uma lâmina ou gume. Agem, inicialmente, afastando as fibras e facilitando a penetração, para depois seccioná-las (FRANÇA, 2008). O melhor exemplo desse tipo de instrumento são as facas. As facas podem ser 
classificadas em um gume (canivete, espada), dois gumes (punhal, faca vazada) e três gumes ou triangular (lima). As lesões são denominadas de perfuroincisas e possuem são mais profundas do que largas. A forma e o trajeto da lesão permite definir qual instrumento foi utilizado (DEL CAMPO, 2009).

\section{Instrumentos perfurocontundentes}

Os instrumentos perfurocontundentes agem inicialmente por pressão em uma superfície para em seguida perfurar a região atingida. As lesões produzidas são denominadas de perfurocontundentes e são típicas dos projéteis de arma de fogo, porém qualquer instrumento com conformação cilindro-ogival é capaz de produzir ferimentos perfurocontusos (DEL CAMPO, 2009).

\section{Instrumentos cortocontundentes}

Apresentam a característica de atuar por pressão exercida sobre uma linha e são influenciados sobre a ação de seu próprio peso ou pela força de quem os maneja, produzindo lesões denominadas cortocontusas. Sua ação se faz por deslizamento, percussão e pressão. Como exemplos temos o machado, golpe de facão, unhas, serra elétrica, entre outros (DEL CAMPO, 2009). A distinção entre os ferimentos cortocontusos e os incisos faz-se pela zona de contusão que existe ao longo das bordas do primeiro e inexiste no segundo.

\section{ENERGIAS DE ORDEM FÍSICA}

São aqueles capazes de modificar o estado físico podendo provocar lesões corporais ou morte. As energias de ordem física são compreendidas entre temperatura, pressão, eletricidade (DEL CAMPO, 2009).

\section{Lesões produzidas pelo calor}

São produzidas por agentes físicos de temperatura elevada, que ao agir sobre os tecidos produzem alterações locais e gerais, cuja gravidade depende de sua extensão ou profundidade. Os agentes mais comumente utilizados são chama, calor irradiante, gases super aquecidos, líquidos escaldantes, sólidos quentes e raios solares. O calor pode atuar sobre o corpo de maneira difusa ou direta, atuando de forma difusa quando a fonte de calor não incide diretamente sobre a aérea atingida, mas sim tornando o meio incompatível com os fenômenos biológicos (DEL CAMPO, 2009). A forma de calor difuso produz os quadros de termonoses, compreendendo a insolação e a intermação (GOMES, 2004). O calor direto produz as queimaduras que podem ser 
simples quando produzidas apenas pelo calor, ou complexas, quando além do calor existem outros fatores como queimaduras por eletricidade, atrito e agentes químicos (DEL CAMPO, 2009).

As queimaduras são classificadas segundo Mélega (2002) de três maneiras diferentes:

- primeiro grau: atinge somente a epiderme. Este tipo de queimadura não provoca alterações hemodinâmicas ou clínicas significativas, visto a ausência de vascularização epitelial. É caracterizada clinicamente pela dor, eritema local e reações da derme subadjacente. Todas as estruturas responsáveis pela reepitelização - queratinócitos e demais células da epiderme, as terminações nervosas livres são preservadas, havendo reepitelização total e sem cicatriz.

- segundo grau: atinge a epiderme e a derme, e também parte dos anexos cutâneos. Clinicamente somam-se aos sinais e sintomas anteriores além da presença de vesículas ou bolhas, superficiais ou profundas.

- terceiro grau: são queimaduras profundas e atingem todas as camadas da pele. Fibras musculares e tecidos ósseos subadjacentes podem ser acometidos. Não apresentam sintomatologia dolorosa e não ocorre reepitalização, levando a perda dos anexos epidérmicos e terminações nervosas epidérmicas e dérmicas. Clinicamente, o aspecto da lesão é céreo, com superfície endurecida, podendo apresentar por transparência vasos sanguíneos esclerosados.

\section{Lesões produzidas pelo frio}

As lesões produzidas pelo frio são denominadas geladuras. Possuem aspecto pálido e anserino, evoluindo para isquemia, necrose ou gangrena. Em humanos o frio pode alterar o sistema nervoso ocasionando sonolência, alterações dos movimentos, insensibilidade dos membros e delírio, na ação generalizada do frio não existe uma lesão típica (DEL CAMPO, 2009). As geladuras são dividas em três graus segundo Croce e Croce Junior (1998):

- primeiro grau: denominada eritema; ocorre em razão da vasoconstrição no nível da pele, com palidez inicial e rubor secundário produzido pela estase sanguínea nas áreas atingidas.

- segundo grau: flictema; em decorrência da estase ocorre transudação do plasma e formação de bolhas similares aquelas observadas nas queimaduras.

- terceiro grau: denominada de necrose ou gangrena; sendo que o sangue coagula no interior dos capilares e, por ausência de irrigação, ocorre morte tecidual.

\section{Lesões produzidas por eletricidade}

A eletricidade qualquer que seja sua origem pode atuar sobre um organismo provocando lesões severas e com frequência, a morte. A eletricidade natural ou cósmica, ocasionada pelos 
raios, pode causar morte chamada de fulminação ou causar lesões corporais, chamadas de fulguração. A eletricidade artificial produz, no local de entrada, uma lesão que com frequência, assume a forma do condutor elétrico que originou a descarga (FRANÇA, 2008). É um ferimento de bordas elevadas e coloração amarelo esbranquiçada e indolor, que recebe a denominação de marca elétrica de Jellinek. Além da marca elétrica, é possível encontrar as queimaduras elétricas, decorrentes do calor produzido pela passagem da corrente no corpo.

Três teorias procuram explicar a morte em decorrência da passagem da corrente elétrica (DEL CAMPO, 2009). Na falência pulmonar, o óbito ocorre pela tetanização dos músculos respiratórios e dos fenômenos vasomotores decorrentes, como edema pulmonar e congestão, essas lesões são observadas A falência pulmonar é observada em tensões entre 120 e 1200 volts. A falência cardíaca sobrevém da fibrilação cardíaca produzida pela passagem da corrente elétrica, ocorrendo em tensões menores, geralmente abaixo de 120 volts. A falência cerebral é observada nas tensões acima de 1200 volts e apresenta como lesões a hemorragia das meninges e demais estruturas do cérebro (DEL CAMPO, 2009).

\section{ENERGIAS DE ORDEM QUÍMICA}

São aquelas que atuam nos tecidos vivos, por meio de substâncias que provocam alterações de natureza somática, fisiológica ou psíquica, podendo levar inclusive a morte. Compreendem os cáusticos e os venenos. Os cáusticos ou corrosivos são substâncias químicas que provocam profunda desorganização dos tecidos vivos, quer por desidratação; quer por efeito da dissolução dos minerais produzindo escaras úmidas e amolecidas, os chamados liquefaciantes como soda e amônia (DEL CAMPO, 2009).

De uma maneira grosseira, todas as substâncias da natureza podem agir como tóxicos, porém nem todos devem ser considerados como tal, portanto não devemos confundir toxicidade, que é a capacidade inerente a uma substância de produzir efeito sobre o organismo, com o risco ou perigo que uma substância oferece. Podemos dizer que dependendo da quantidade e desde que absorvida, qualquer substância poderá ser considerada veneno (DEL CAMPO, 2009).

Por uma variedade de razões, a incidência anual de intoxicações intencionais em animais não pode ser corretamente determinada. Na maioria das vezes, a intoxicação intencional não é percebida por proprietários, ocasionando em confusões com outras doenças de causas infecciosas, metabólicas ou outras condições. Em muitos casos é assumido que a intoxicação intencional ocorre quando os animais são expostos ao agente tóxico no ambiente (MERCK, 2007). Apesar da ampla variedade de venenos existentes, a maioria dos casos de envenenamento ocorre por 
rodenticidas anticoagulantes, etilenoglicol, inseticidas organofosforados, carbamatos e cafeína (MERCK, 2007).

\section{ENERGIAS DE ORDEM FÍSICO QUÍMICA}

O termo asfixia, do grego asphuksía, indica "falta de pulso" sendo utilizado para indicar a supressão da respiração. O termo, no entanto, é abrangente e pode englobar várias causas de morte. Para a medicina legal somente interessam aquelas que apresentam três características: primitivas (quanto ao tempo), violentas (quanto ao modo) e mecânicas (quanto ao meio) (DEL CAMPO, 2009).

Entende-se por asfixia primitiva aquela que é a causa primária da morte, e não consequência de algum fenômeno prévio. Violenta é toda a asfixia que não decorre de processo natural, mas é produzida por agente mecânico (DEL CAMPO, 2009). Respeitadas essas características, interessam a medicina legal apenas as asfixias por enforcamento, estrangulamento, esganadura, sufocação direta ou indireta, afogamento e imersão em atmosfera de gases irrespiráveis (DEL CAMPO, 2009).

Nos processos que cursam com asfixia, observam-se duas fases: irritação e esgotamento. $\mathrm{Na}$ fase de irritação ocorre dispnéia inspiratória consciente por cerca de 1 minuto, seguida por dispnéia expiratória inconsciente por cerca de 3 minutos. A fase de esgotamento é dividida em período inicial e terminal, sendo o período terminal de duração de 3 minutos até a morte (CROCE; CROCE JUNIOR, 1998). As asfixias possuem como características cianose da pele, equimose das conjuntivas, resfriamento cadavérico lento, congestão das vísceras e fluidez sanguínea (FRANÇA, 2008).

As equimoses viscerais ou manchas de Tardieu são petéquias hemorrágicas encontradas em quase todos os casos de asfixia mecânica, principalmente nos pulmões, e decorrem da ruptura dos capilares pela alta pressão arterial provocada pelo aumento da concentração de gás carbônico no sangue (FRANÇA, 2008).

\section{Enforcamento}

O enforcamento pode ser definido como a constrição do pescoço por baraço mecânico (corda ou cordel) tracionado pela força peso do próprio corpo. O sulco do enforcamento é caracterizado por possuir sulco oblíquo, descontínuo, sendo interrompido na altura do nó e desigualmente profundo (DEL CAMPO, 2009). A asfixia ocorre pela obliteração completa da traqueia. Pode ocorrer, entretanto, na dependência da posição e conformação do baraço mecânico, 
o fechamento da glote por fratura ou pela projeção do osso hioide contra a faringe (DEL CAMPO, 2009).

De acordo com Del Campo (2009) a morte por enforcamento pode ocorrer por três mecanismos:

- por asfixia mecânica: a constrição do pescoço pode obliterar as vias respiratórias, produzindo a morte;

- por inibição: a constrição lesa os nervos vagos e seios carotídeos, determinando a parada cardiorrespiratória e consequente morte;

- por obstrução da circulação: até mesmo uma pequena pressão no pescoço pode determinar a interrupção da circulação para o cérebro, ocasionando morte.

\section{Estrangulamento}

O estrangulamento pode ser definido como a constrição do pescoço por baraço mecânico (corda ou cordel) acionado por força estranha ao peso do próprio corpo. É comum a ocorrência do sulco de estrangulamento nos sentidos transversal e horizontal, podendo eventualmente ser oblíquo. É contínuo e homogêneo em relação a profundidade, uma vez que não existe o nó típico do enforcamento. Os mecanismos da morte por estrangulamento são semelhantes aos observados no enforcamento (DEL CAMPO, 2009).

\section{Esganadura}

A esganadura é a asfixia mecânica pela constrição ântero lateral do pescoço produzida pela ação direta das mãos do agente. Não há sulco que cede seu lugar para marcas ou estigmas ungueais e diversas escoriações, equimoses e hematomas. Com certa frequência é notada a fratura do osso hioide. A etiologia da morte por esganadura tem sido explicada mais pelos fenômenos de inibição nervosa decorrentes da compressão do pescoço (inibição vagal ou choque vagal) do que a asfixia propriamente dita (GOMES, 2004).

\section{Sufocação}

A sufocação é a asfixia mecânica decorrente do bloqueio direto ou indireto das vias respiratórias impedindo a penetração do ar. A oclusão dos orifícios externos respiratórios é praticada com as próprias mãos ou com a utilização de agentes moles como travesseiros ou almofadas. A obstrução das vias respiratórias é com frequência acidental e ocorre pela aspiração de corpos estranhos (alimentos, pequenos brinquedos etc) (DEL CAMPO, 2009). 


\section{Afogamento}

É a modalidade de asfixia mecânica em que há penetração de líquido nas vias aéreas. Não há necessidade de imersão total do corpo, bastando que as vias aéreas estejam submersas impedindo a respiração. Segundo França (2008) a morte por afogamento se desenvolve em três fases:

- fase de resistência: nela a vítima tenta conter a respiração o máximo possível;

- fase de exaustão: na qual, por reflexos bulbares, a vítima passa a inspirar o líquido profundamente;

- fase de asfixia: comina com a perda da consciência, convulsões e morte.

Abaixo temos os principais sinais externos e internos dos afogados segundo Croce e Croce Junior (1998):

Sinais externos

- lesões por animais aquáticos.

- cianose da face: aparece na maior parte das asfixias.

- pele anserina: corresponde ao eriçamento dos pêlos, conhecido como sinal de Bernt.

- maceração da pele: a epiderme fica infiltrada de água, principalmente nas mãos e pés.

- lesões de arrasto: ocorrem pelo embate do corpo no leito do curso de água.

- rigidez cadavérica precoce: pela baixa temperatura da água e choque térmico provocado.

Sinais internos

- diluição do sangue: a ingestão de grande quantidade de água acaba por fluidificar o sangue em razão do equilíbrio osmótico rompido.

- cogumelo de espuma: o plasma sanguíneo passa para o alvéolo e ocorre grande formação de espuma, que preenche a árvore respiratória saindo pela cavidade oral, tal sinal é muito comum em humanos afogados.

- presença de líquido no ouvido médio.

\section{ENERGIA DE ORDEM BIODINÂMICA - CHOQUE}

Sob a designação genérica de choque, termo derivado do inglês shock, englobam-se todos os estados clínicos em que o organismo não consegue sustentar o equilíbrio circulatório desejado para a manutenção dos fenômenos biológicos, quer em decorrência da descarga insuficiente do coração, quer por diminuição do volume circulatório (CROCE; ROCE JUNIOR, 1998).

Choque é uma síndrome, um conjunto de sintomas decorrentes de causas diversas, mas relacionados com a queda acentuada e rápida da pressão arterial e venosa. O pulso aumenta em 
frequência, porém diminui em amplitude (taquisfigmia e pulso filiforme), as mucosas apresentam-se cianóticas, a respiração diminui, o débito urinário diminui, e se não ocorrer pronta reversão do quadro, ocorre perda da consciência, acidose metabólica e morte (DEL CAMPO, 2009).

Quanto ao momento em que se instala, o choque pode ser classificado em primário ou secundário. Será primário se a síndrome se manifestar imediatamente após a ocorrência da causa e, secundário se, o fator determinante do choque e o início dos sintomas caracterizadores da síndrome, existir um lapso de tempo significativo (DEL CAMPO, 2009). Quanto a origem o choque pode ser classificado em cardiogênico, obstrutivo, hipovolêmico ou periférico. O choque cardiogênico ocorre normalmente nos casos de infarto do miocárdio e é caracterizado por uma rápida diminuição da capacidade de bombeamento do coração. O choque obstrutivo advém de um bloqueio da circulação de retorno, por exemplo, nos casos de trombose, obstrução da veia cava, tumores, embolias e aneurismas (CROCE e CROCE JUNIOR, 1998).

O choque hipovolêmico é resultante da redução abrupta do volume sanguíneo total, quer que seja por hemorragia, perda de plasma ou liquido extracelular. O choque periférico compreende várias modalidades, de acordo com sua etiologia. Será septicêmico se resultar de processos infecciosos agudos causados por bactérias, principalmente, liberando endotoxinas e levando a um desequilíbrio da circulação periférica. O choque anafilático é observado principalmente em pessoas portadoras de hipersensibilidade alérgica a determinadas substâncias, com liberação de histamina e violenta vasodilatação periférica. $O$ choque neurogênico pode ser desencadeado por fortes distúrbios emocionais, dor intensa, esforço excessivo ou em decorrência de ação reflexa e nos traumatismos de coluna (CROCE; CROCE JUNIOR, 1998).

Alguns autores mencionam o choque por embolismo do líquido amniótico, tratando-se de uma modalidade de choque obstrutivo que ocorre particularmente em recém nascidos por aspiração de líquido amniótico ou mecônio, levando a um quadro de cor pulmonale agudo (CROCE; CROCE JUNIOR, 1998).

\section{CONCLUSÃO}

A Medicina Veterinária Legal é uma das áreas em Medicina Veterinária que mais vem ganhando destaque nos últimos tempos. Apesar de ser uma área de atuação com mais de 80 anos, a mesma necessita ser melhor estudada e trabalhada, além da necessidade de formar mais profissionais nessa área. Dentro da Medicina Veterinária Legal, a Traumatologia Forense é uma área extremamente aplicável, pois através dela é possível a identificação de um determinado objeto utilizado em um caso de trauma, além das lesões que esse objeto causou no organismo 
animal. É também de extrema importância a área de toxicologia veterinária, identificando elementos químicos responsáveis tanto pela intoxicação de animais quanto em práticas antiesportivas.

\section{REFERÊNCIAS}

BANDARRA, E.P. Tanatologia: Fenômenos Cadavéricos Abióticos. Revista de Educação Continuada do CRMV-SP, São Paulo, v.2, n. 1, p. 59-63, 1999.

CROCE, D.; CROCE JÚNIOR, D. Manual de Medicina Legal. São Paulo: Saraiva, 1998, 860p.

DEL CAMPO, E. R. A. Medicina Legal I. $6^{\text {a }}$ ed, São Paulo: Saraiva (Coleção Cursos \& Concursos), 2009, 120p.

DI MAIO, V.J.; D. DI MAIO. Forensic Pathology, $2^{\mathrm{a}}$ ed. Boca Raton, Flórida: CRC Press, 2001, $592 p$.

FRANÇA, G. V. Medicina Legal. $8^{a}$ ed., Rio de Janeiro, Guanabara Koogan, 2008, 330p.

GOMES, H. Medicina Legal. Atualizador Hygino Hercules. 33ª ed, Rio de Janeiro, 2004, 22p.

LEI ${ }^{\circ}$ 5.517, de 23 de outubro de 1968. Disponível em:

http://www.cfmv.org.br/portal/legislacao/leis/lei_5517.pdf. Acesso em: 19/11/2015.

MARLET, E.F.; MAIORKA, P.C. Analise retrospectiva de casos de maus-tratos contra cães e gatos na cidade de São Paulo. Braz. J. Vet. Res. Anim. Sci., São Paulo, v. 47, n 5, p. 385-394, 2010 .

MÉLEGA, J. M. Cirurgia plástica - fundamentos e arte: princípios gerais, Rio de Janeiro, $1^{\text {a }}$ ed, Médisi, 2002.

MERCK, M. Veterinary forensics: animal cruelty investigations. $1^{\mathrm{a}} \mathrm{ed}$, Ames- Iowa, Blackwell Publishing, 2007, 327p. 